\title{
Creating Mechanisms of Eco-friendly Apple Cultivation and Raising Health Awareness Using Information Technology
}

\author{
Takeshi Maeda ${ }^{1 *}$, Toshihiro Okabe ${ }^{2}$ and Junichiro Sasaki ${ }^{1}$ \\ 1 Graduate School of Regional Studies, Hirosaki University, Hirosaki 036-8560, Japan \\ 2 Molecular Engineering Institute, Kindai University, Iizuka 820-8555, Japan \\ * e-mail: h13gr107@,hirosaki-u.ac.jp
}

\begin{abstract}
In Aomori Prefecture, several problems have become major issues. Namely, those of individuals' insufficient environmental awareness (open burning in agricultural work including apple cultivation, etc.), the lowest life expectancy in Japan (Aomori is the prefecture with the lowest average life expectancy for both men and women nationwide), and the seriousness of the economic situation (individual incomes in Aomori are the lowest in the country). Separate solutions have been adopted for each of these problems, but the effectiveness of such solutions is doubtful. Each problem is conceivable in itself as both a cause and an effect. So we need to solve them all simultaneously. Each previous solutions had common goals of expanding social education. Therefore, our research aims to create a mechanism to solve the above problems at the same time by creating necessity to participate in social education, researching apple cultivation which is representative agriculture in Aomori prefecture. The mechanism comprises three systems. The "LCA / Business Support System", the "Traceability System" and the "Education Point Payment System". For the present study, we created a tool for inputting work data and running life cycle assessments (LCAs) to act as the LCA / Business Support System, and then carried out a data entry and LCA test-run. As a result, we confirmed that this tool can be constructed inexpensively and that the user can easily ascertain the situation of environmental burden and work which needs improvement. This also confirms the possibility of using this mechanism to create motivation for change by necessity.

Key words: apple cultivation, environmental impact assessment, traceability system, social education
\end{abstract}

\section{INTRODUCTION}

In Aomori Prefecture, the advancement of agricultural technology has also seen progress in terms of reducing the environmental burden of apple cultivation. However, there are still processes in place that have a significant environmental impact. We need to raise environmental awareness on an individual level. Additionally, average life expectancy in Aomori Prefecture is the lowest in Japan, for both men and women, and this is considered problematic. Again, individual income is in the lowest group in domestic rankings.

Separate solutions have been adopted for each of these issues. For example, to help with the life expectancy problem, the Hirosaki University School of Medicine conducts health lectures in areas throughout the prefecture, aiming to increase residents' health awareness. In the apple industry, various organizations host workshops, and the prefecture works to expand the market (including overseas exports) to increase income. There are also various organizations working on environmental education.

However, the primary goal of many of these activities is to raise the level of social education. We can suppose that people who already have a high level of awareness make up the majority of participants. The question remains as to whether or not those who are truly in need of support are attending. The above problem is conceivable in itself as both a cause and an effect. Each can be considered both a cause and an effect. So we need to solve them all simultaneously.

Our research plans to raise the level of social education by creating the necessity to participate therein. Our goal is to create a mechanism that will also, as a result of this, lead to the simultaneous resolution of the issues outlined above.

\section{PRECEDENT CASE}

We can easily imagine how a lack of education would influence many issues, environmental, medical, and otherwise. This suggests that ongoing education would lead to the mitigation or resolution of various problems.

We would like to submit the case of what was formerly called Sawauchi Village in Iwate Prefecture as a precedent for our approach. The region used to be very poor, and had the highest infant mortality rate in Japan. Through the mayor's robust social education project, however, in a short period of time they became the first in Japan to achieve an infant mortality rate of zero. The project also led to the development of a self-starting regional industry. The mayor's strong leadership was certainly instrumental in their success, but we can also submit as equally instrumental the powerful motivation effected through social situation, i.e., that which came from realizing that the shadow of death was close at hand, approaching 
steadily.

The principal objective of Our research takes creating motivation for people to become socially educated. We focus specifically on adding motivation through economic merit.

\section{METHODS}

\subsection{System configuration}

The mechanism comprises three systems. First, we aim to raise awareness of the environmental burden as well as toward making work lighter and more efficient through a system that ascertains the environmental burden of apple cultivation and provides work support (First-level system, Fig. 1). Next, using a system that discloses information to consumers, the data on agricultural work (amount of pesticides and fertilizers used and amount of fuel consumed) and on the environmental burden that were compiled using First-level system are presented to the consumer in as both product safety information and information on the product's contribution to the global environment. This is designed to increase the producer's income by increasing products' added value (Second-level system, Fig. 2). Finally, we aim to increase the level of social education using a system that pays fees for using the above two systems using a unique point, which points can be obtained by attending social education lectures or going for medical examinations (Third-level system, Fig. 3). Here, we construct and verify the first-level system that acts as the driving force for the overall mechanism. The first-level system's concrete functions and purpose are as follows:

Functions: Registers work content, work time, equipment and fuel used, pesticides, etc. Also carries out LCAs (Life Cycle Assessments) based on registered data; the timing for said LCAs is adjustable. The system is operated via an information terminal such as a PC or mobile phone.

Purpose: To increase awareness in terms of both the environment and improving business.

[First-Level]LCA/Business Support System

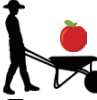

LCA Result / Business Support

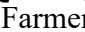

Work data

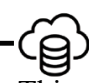

This

Fig.1. First-level system outline (LCA / Business Support System)

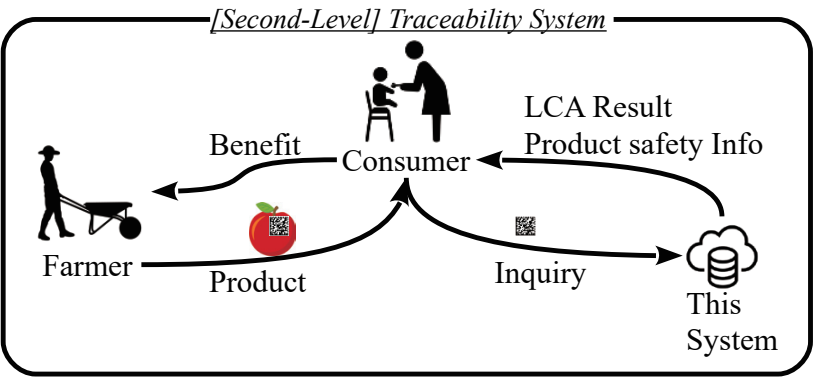

Fig.2. Second-level system outline (Traceability System)

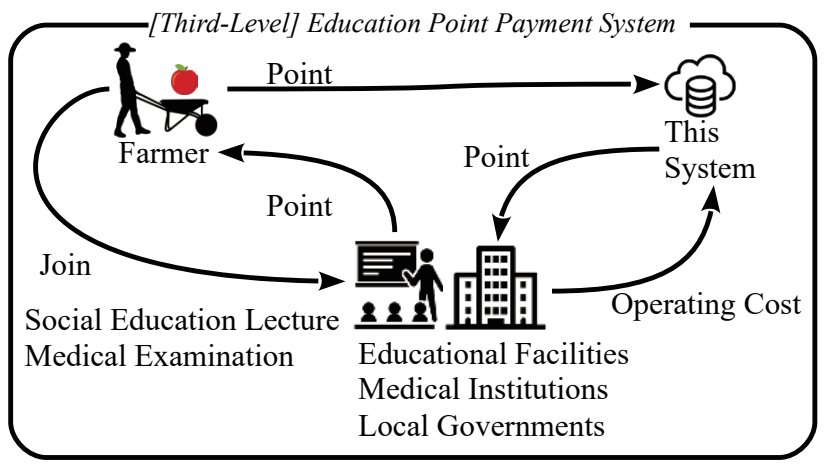

Fig.3. Third-level system outline (Education Point Payment System)

\subsection{System Construction}

For this project, we built the system on Google Drive. Google Drive is a form of cloud storage (like a hard drive on the internet) that can be used by anyone having a Google account, which can be created free of charge. Our reasons for using Google Drive are as follows:

a) A set amount of data can be stored at no charge.

b) The file sharing function allows anyone to view data.

c) It allows for building applications.

d) Data can be kept securely.

The file structure is as follows:

1) Google site

- Comprises the Main Menu, and displays links for various functions

2) Google Forms

- Input screen for basic data and daily work data

3) Google Spreadsheets

- Save input data

- Output LCA calculations and results (.pdf file)

- Output business reports (.pdf file)

- Output a link for viewing LCA results as a 2D code (.pdf file)

4) PDFs

- Save data output from spreadsheets

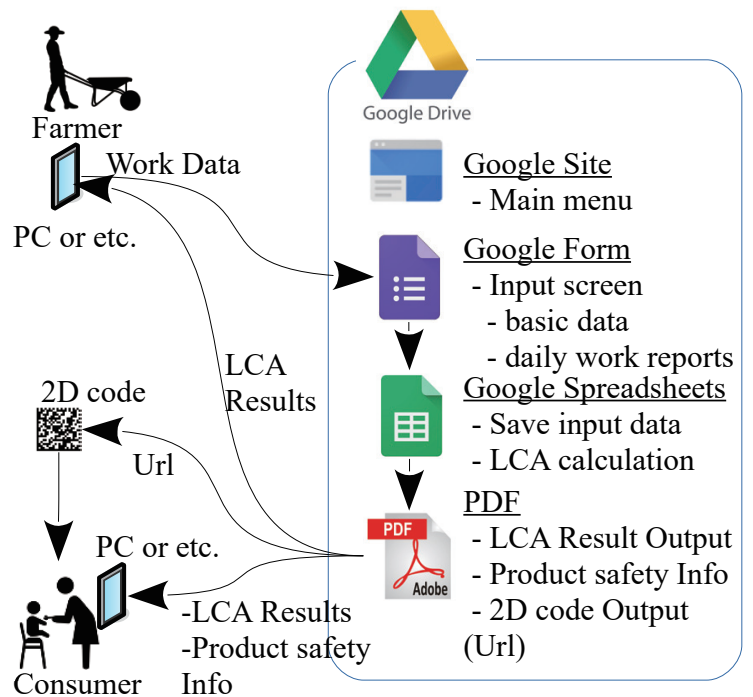

Fig. 4 System file relationships 


\section{RESULTS}

We created the "LCA / Business Support System" (first-level system) and tested it at the following farm (Fig. 5 , Table 1).

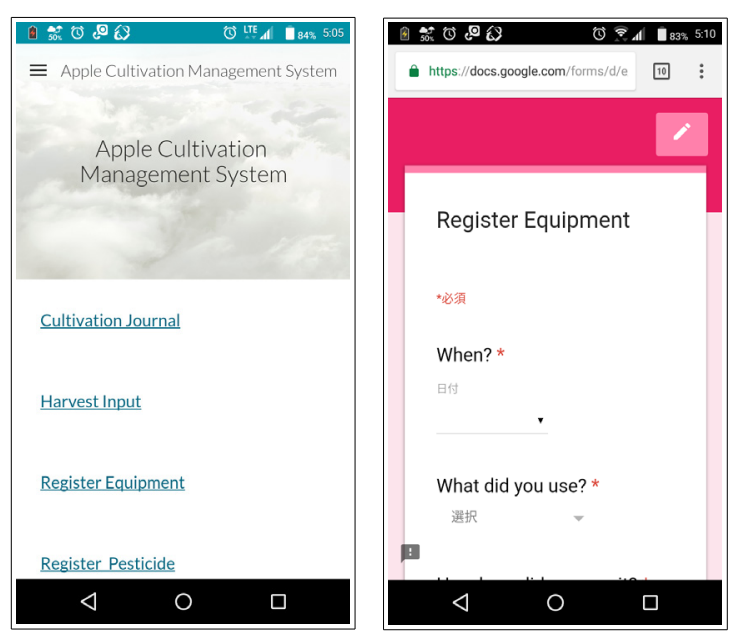

Fig.5. Screen shots of the "LCA / Business Support System" (first-level system) running on a smartphone.

Table 1. About the Test Farm

\begin{tabular}{|l|l|l|}
\hline & Item & Content \\
\hline 1 & Location & $\begin{array}{l}\text { kusanagi Omori, Hirosaki-shi, Aomori- } \\
\text { ken, Japan }\end{array}$ \\
\hline 2 & Land Area & 45 ares \\
\hline 3 & Apple Crops & Fuji, Hirosaki Fuji, Jona Gold, Orin \\
\hline 4 & Usage Data & $\begin{array}{l}\text { Fuel consumption (yearly average), } \\
\text { Amounts of fertilizer and pesticides } \\
\text { used (2016 pest control calendar), Days } \\
\text { worked, Fertilizer and pesticide prices } \\
\text { (2016 fiscal year) }\end{array}$ \\
\hline 5 & $\begin{array}{l}\text { LCA } \\
\text { Calculation } \\
\text { Method }\end{array}$ & $\begin{array}{l}\text { From the manual for Life Cycle } \\
\text { Assessment of Agricultural Practices in } \\
\text { Japan }\end{array}$ \\
\hline 6 & LCA Object & $\mathrm{CO}_{2}$ \\
\hline
\end{tabular}

In the LCA results (Fig. 6 - Fig. 8), we can see that the percentages of $\mathrm{CO} 2$ emissions from fertilizers and pesticide spraying were high in comparison with other operations. The fuel consumption data shows us that mowing grass produces a high level of $\mathrm{CO} 2$ emissions. The most effective way to reduce the environmental burden would be to reduce the amount of pesticides being sprayed, as they account for the greater part of $\mathrm{CO} 2$ emissions (Fig. 6, Fig. 7). The next largest $\mathrm{CO} 2$ emission levels come from fuel consumption. That mostly from mowing grass, if we omit fuel consumption by commuter vehicles (Fig. 6, Fig. 8). Mowing is performed to make it easier for pesticide spraying vehicles and transport vehicles to pass through. If we think from the standpoint of fuel consumption, however, the $\mathrm{CO} 2$ emission levels calculated from fuel consumed by mowing equipment is overwhelmingly large. By restricting grass mowing operations, we can reduce overall cost and lower the environmental burden.

Thus this LCA results can be used to ascertain operations' environmental burden and it can also serve as base data for improving work efficiency. From the above, it was confirmed that this tool can provide basic data for to ascertain the environmental burden of the project and improving work efficiency despite the fact that the system maintenance cost is free. This shows that we can provide useful tools for farmers who were abandoning informationization due to cost problems.

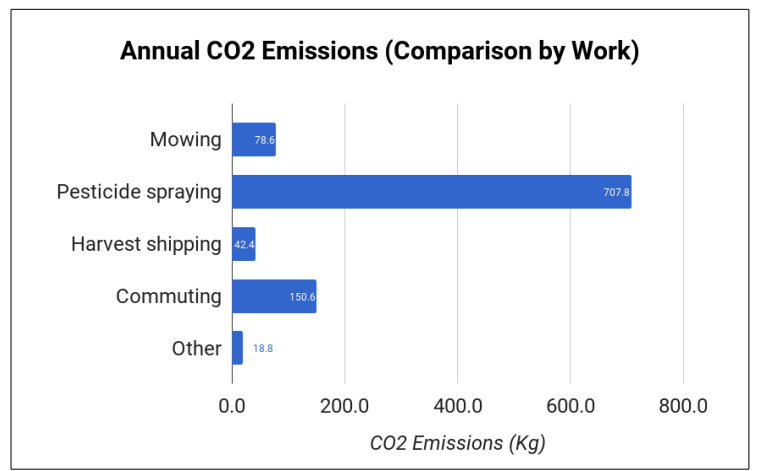

Fig.6. Annual CO2 Emissions (Comparison by Work)

\section{Annual CO2 Emissions (Comparison by Emission Source)}

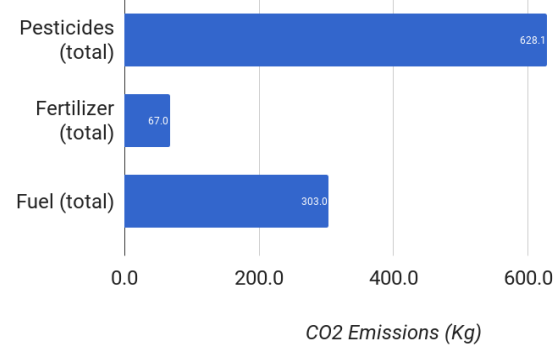

Fig.7. Annual CO2 Emissions (Comparison by Emission Source)

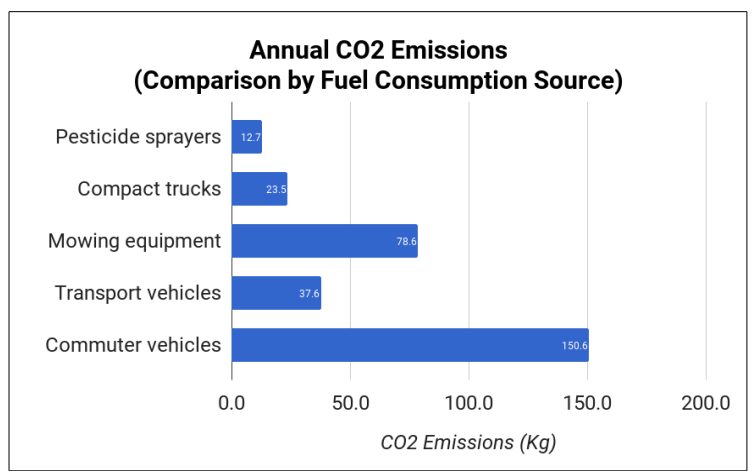

Fig.8. Annual $\mathrm{CO} 2$ Emissions (Comparison by Fuel Consumption Source)

\section{SUBSEQUENT RESEARCH}

We will verify the second level system and the third level system in the future. The functions and purposes of each system are as follows:

1) Second-level System (Traceability System)

Functions: Publishes LCA results, information concerning 
pesticides, fertilizer, and fuel used in agricultural operations, etc. 2D codes affixed to products can be read using a PC or mobile phone in order to view the above information.

Purpose: To increase products' added value by providing the consumer with product safety information as well as indicating contributions to the global environment. It is designed to result in increased incomes for farmers.

2) Third-level System (Education Point Payment System)

Functions: Users pay fees for using the system via education points. Users can obtain the system's education points from institutions where they attend lectures or go for medical examinations. The system's operating institution cashes the education points via the medical and educational institutions to obtain operating costs. Local governments pay operating fees to the system's operating institution in the form of outsourcing fees for health and sanitation or social education projects, corresponding to the number of education points.

Purpose: Aims to improve various social issues by raising social education standards and increasing the rate of medical examinations. Again, by using an indirect payment system, it also holds the goal of promoting the introduction of technology into fields for which obtaining direct profits is difficult.

\section{CONCLUSIONS}

The authors of this study created tools for inputting work data and running LCAs, and then used said tools to test-run data entry and LCAs. Results confirmed that even if the system operation cost is free, by performing a few simple procedures, we can ascertain the status of operations' burden on the environment and identify which operations need to be improved upon. However, apple farmers and local municipal workers pointed out the following problems during interviews:

- Since many agricultural workers are elderly, system operations need to be simplified (barrier-free).

- There are doubts as to whether we can truly actualize the aspect linking education points to the real economy (monetization). Specifically, if local municipalities participate, we will need to eliminate any sense of unfairness between industries.

From here on out, we would like to verify the overall system's effectiveness, which includes resolving the above issues. Lastly, the mechanism emphasizes creating strong motivation toward the third level (social education), using the first-level and second-level systems as a trigger. At present, we are planning on creating said triggers via LCAs and the Traceability System, but from here on we would also like to consider system construction in terms of offering functions with greater added value for farmers.

\section{References}

[1] Dokuritsu Gyosei Hojin Nogyo Kankyo Gijutsu Kenkyujo. 2003. LCA Teho wo Mochiita Nosabutsu Saibai no Kankyo Eikyo Hyoka Jissen Manyuaru (Manual for Life Cycle Assessment of Agricultural Practices in Japan). Dokuritsu Gyosei Hojin Nogyo Kankyo Gijutsu Kenkyujo.

[2] Hirosaki Daigaku Nogaku Seimei Kagakubu Fuzoku Miriyo Baiomasu Kenkyu Senta. 2006. Miriyo Baiomasu toshite no Ringo Senteieda no Riyo - Sono Kadai to Chiiki-nai Renkei - Dai Ikkai Miriyo Baiomasu Semina Hokoku Shiryo Shu. Hirosaki Daigaku Nogaku Seimei Kagakubu Fuzoku Miriyo Baiomasu Kenkyu Senta.

[3] Inaba, A., editor. 2014. Gakushu de manabu LCA. Mito Kagaku Gijutsu Kyokai.

[4] Kikuchi, T. 1968. Jibuntachi de Inochi wo Mamotta Mura. Iwanami Shinsho.

[5] Oikawa, K. 2008. Soncho Ariki - Sawauchimura Masao no Shogai. Renga Shobo Shinsha.

[6] Ota, S., et. al. 1983. Sawauchimura Funtoki - Jumin no Inochi wo Mamoru Mura. Akebi Shobo.

(Received August 15, 2017; Accepted March 15, 2018 ; Published Online June 1, 2018) 